\title{
OPTIMIZED PLACEMENT OF CONNECTING THE DISTRIBUTED GENERATIONS WORK STAND ALONE TO IMPROVE THE DISTRIBUTION SYSTEMS RELIABILITY
}

\author{
Hamed Hashemi-Dezaki - Ali Agheli - \\ Behrooz Vahidi - Hossein Askarian-Abyaneh *
}

\begin{abstract}
The use of distributed generations (DGs) in distribution systems has been common in recent years. Some DGs work stand alone and it is possible to improve the system reliability by connecting these DGs to system. The joint point of DGs is an important parameter in the system designing. In this paper, a novel methodology is proposed to find the optimum solution in order to make a proper decision about DGs connection. In the proposed method, a novel objective function is introduced which includes the cost of connector lines between DGs and network and the cost of energy not supplied (CENS) savings. Furthermore, an analytical approach is used to calculate the CENS decrement. To solve the introduced nonlinear optimization programming, the genetic algorithm (GA) is used. The proposed method is applied to a realistic 183-bus system of Tehran Regional Electrical Company (TREC). The results illustrate the effectiveness of the method to improve the system reliability by connecting the DGs work stand alone in proper placements.
\end{abstract}

Keywords: stand alone distributed generations, distribution systems, genetic algorithm (GA), system reliability, energy not-supplied (ENS)

\section{Nomenclatures}

$T$ Total number of customers connected to distribution system

$O F \quad$ Objective function of the proposed optimization problem

$m b \quad$ Number of sections located in main branch

$\lambda_{m i} \quad$ Failure rate of $i$-th section located in main branch

$\lambda(s, p) \quad$ Failure rate of $p$-th section located in s-th lateral branch

$N_{m i} \quad$ Number of customers supplied through $i$-th section of main branch

$L_{m i} \quad$ Amount of customer loads supplied through $i$-th section of main branch

$\beta \quad$ Set of candidate sections to connect a distributed generation $(\mathrm{DG})$

$f l b(i) \quad$ First downstream lateral branch of section $i$ located in main branch

$N(s, p)$ Number of customers supplied through $p$-th section of $s$-th lateral branch

$L(s, p) \quad$ Amount of customer loads supplied through $p$-th section of $s$-th lateral branch

$t s(s) \quad$ Number of sections located in s-th lateral branch

$b l b(i) \quad$ First upstream lateral branch of section i located in main branch

$f d m b(i)$ First downstream main branch of i-th lateral branch

fumb $(i)$ First upstream main branch of i-th lateral branch

$X_{s i} \quad$ Binary variable indicates the existence or not existence of a switching device in section $i$

$M_{1} \quad$ Annual restoration energy by using DGs, in kVA
$M_{2, i} \quad$ Required investment to connect a DG to section $i$

$Y_{i} \quad$ Binary variable indicates section $i$ is a suggested placement to allocate a DG in accordance to the selected scenario

$K_{1} \quad$ Accumulative coefficient based on the project life time and other engineering economic parameters

$K_{2} \quad$ Cost of interrupted loads per kWh

$G \quad$ Generation size

I Algorithm iteration

$N P W \quad$ Net present value of cash flow

$n \quad$ Project life time

$r \quad$ Annual load growth coefficient

$p \quad$ Profit rate

$B_{i} \quad$ Saved cost of year $i$

$S_{D G_{i}} \quad$ Maximum capacity of generation of $i$-th DG

$D_{i} \quad$ Length of section $i$

$L_{i} \quad$ Load of section $i$

$\lambda_{i} \quad$ Failure rate of section $i$

$P_{r} \quad$ Power capacity of DG $r$

\section{INTRODUCTION}

The main objective of the planning and operation of electric power distribution systems is to satisfy the system load and energy requirements as economically as possible with a reasonable assurance of continuity and quality. The two aspects of relatively low cost electrical energy at a high level of reliability are often in direct conflict due to the fact that providing a higher level of reliability

\footnotetext{
* Electrical Engineering Department, Amirkabir University of Technology, No. 424, Hafez Ave., Tehran, 1591634311 Iran, hamed.hashemi@gmail.com
} 


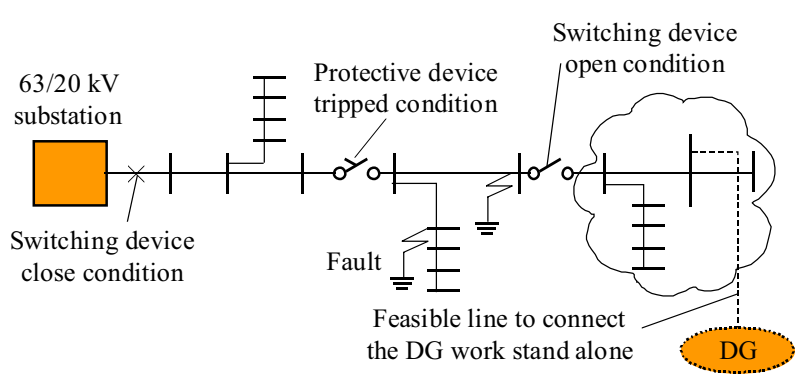

Fig. 1. Energy restoration in a typical distribution system

will cost utilities more in capital and operational expenditures. This has become the justification to emphasize on the optimization of system costs and reliability $[1,2]$. To improve the distribution systems reliability, some studies have been reported on finding the best placement of protective and switching devices [2-7], decreasing the failure rates of system components $[2,8]$, adding protective devices [9], reclosing $[10,11]$, reconfiguration [12] and using distributed generations (DGs) $[13,14]$.

Recent years have witnessed a trend towards the development of DGs. The distribution systems have been usually designed to operate with unidirectional power flow. Adding DG to a distribution system imposes a different set of operating condition on the network, such as voltage rise, power loss reduction, stability problems and reliability increasing. The placement of DG connection to system plays a great part on the effects of DG [11-18]. Therefore, researchers tempt to find appropriate methods for optimal placement of DG to improve system characteristics such as reliability increasing and power losses reduction $[11,15]$. Most of the studies on DGs sizing and siting have focused on finding the optimized placement based on minimizing the system power losses [19]. Other system parameters such as voltage profile, total harmonic distortion (THD) and reliability have been studied, too $[20,21]$.

In distribution systems, a number of utilities and companies use local generation to provide their electrical consumes in both normal and emergency conditions. These DGs work stand alone and by connecting them to the AC network in different conditions, it is possible to decrease energy not supplied (ENS) and increase the system reliability. The joint point of connecting the DG to main network is very important because the placement of connectivity changes the network topology. If the cost of the connecting line and other required devices is venial, the best scenario is the connection of all DGs. This assumption, nevertheless, is not reasonable, since the cost of DG connection to network is considerable. In this way, the connection of all DGs is not economical and the previous choice cannot be the best. To find the optimal solution, a compromise between the cost of ENS (CENS) decrement and that of required connector line is necessary.

According to the above problem statement, the comparison between the cost of DG connection and reliability improvement is necessary. An optimum solution suggests some DGs to connect the main network, not all of them.

The proposed approach tries to find the optimized placement of DG connection to main network. The new method is applicable in both operating and designing conditions. The optimized solution is equal to maximized restoration energy using DGs. Through the application of the proposed method to distribution systems, it is possible to find the optimized energy restoration by DG installation in proper points. If the restorative energy increases, the reliability indices are improved. ENS decrement is directly relevant to the improvement of other indices such as system frequency average interruption index (SAIFI) and system duration average index (SAIDI).

Furthermore, a novel method is proposed to calculate the value of restoration energy that can be achieved by installation of the DG in distribution system. The objective function includes two main terms: CENS decrement by DG connection and the cost investment of connector lines installation.

The objective function is optimized by genetic algorithm (GA). The optimized results determine in which points of distribution system, DG connection is more effective and useful to improve the system reliability. The proposed method is applied to a realistic distribution system of Tehran Regional Electrical Company (TREC). The results illustrate that by connecting the DGs work stand alone to network in appropriate locations, it is possible to improve the system reliability effectively and economically.

\section{PROBLEM STATEMENT}

ENS would be decreased by connecting the DGs work stand alone. The possibility of connecting some DGs to network increases the restoration energy. In view point of reliability increase by connecting the DG to network, the joint point to connect the DG is very important. Finding the joint point of DGs is useful for operating and designing conditions.

When a fault occurs in the main or lateral sections, the first upstream protective device senses the fault and separates the downstream loads from power supply. Now, if there is the ability to provide the interrupted loads, a proportion of interrupted loads can be restored. This restoration energy occurs through using the switching devices and maneuver strategy. The schematic of energy restoration in a typical distribution system is shown in Fig. 1.

The value of the restoration energy is a function of network topology, protective and switching devices as well as other power supplies that can provide the interrupted loads such as DGs shown in Fig. 1. So the switching and protective devices and position of DGs connection are considered to be important and change the amount of restoration energy.

The problem of finding the solution that demonstrates the proper position of connecting the DG is different in 

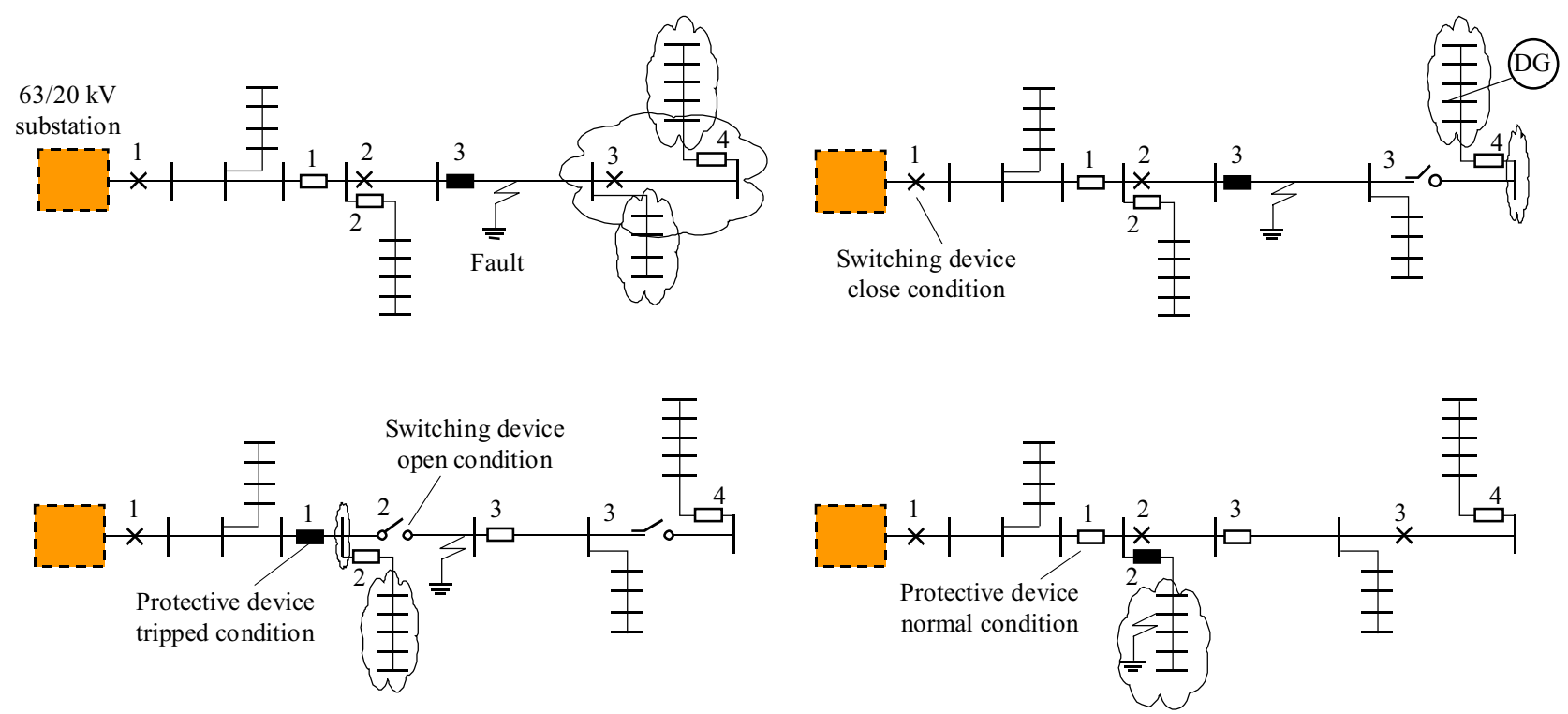

Fig. 2. Typical distribution system: (a) - interrupted area due to a fault occurrence in the main section, (b) - restorable interrupted area due to a fault occurrence in the main section with DGs, (c) - restorable interrupted area due to a fault occurrence in the main section switching and main supply, (d) - limited interruption area in lateral branch due to the fault occurrence in one with a protective device

view point of design and operating distribution system. If the system is in design process, the problem variables are the number and placement of DG connections. In such conditions, all sections are feasible to connect the DG to network, but if the system is in operating conditions, there are some disconnected DGs. Therefore, the candidate connecting points are the nearest place to the available disconnected DGs. The optimized solutions in this condition are binary variables indicating the connecting or disconnecting the available DGs to network, while the optimized solutions in designing process are integer variables indicating the connecting placement. The summation of the suggested connecting points should be less than the number of the expected DGs. The obtained solutions in design view help determine the supportive strategy to develop the DGs where they are more useful to improve the system reliability.

\section{PROBLEM FORMULATION}

If the reliability improvement of DGs connection is venial, the best scenario is the connection of all DGs. By considering the required cost of DG connection, the previous strategy cannot be the best. In this situation, the comparison between CENS and cost of required transmission line is not unavoidable. In this paper, using a new objective function to determine the best solution for the finding of the number and placement of the interconnected DGs, a novel approach is introduced.

The proposed objective function includes two main terms: the benefit of energy restoration by DG connection and the cost investment to install of the connector line to connect DG to distribution system. To calculate the value of restoration energy that can be achieved by installation the DG in distribution system, a mathematical method is presented. By using this analytical method, the speed of calculation is increased. The proposed objective function is demonstrated as

$$
O F=K_{1} \times K_{2} \times M_{1}-\sum_{i \in \beta}\left(Y_{i} \times M_{2, i}\right) .
$$

In this paper, a novel analytical model is proposed to calculate the value of the restoration energy by using DG in distribution systems. An advantage of the proposed analytical model to calculate the different system characteristics is its high speed. Additionally, when the mathematical model is provided to calculate the system characteristics, it is simplified to do the sensitive analyses of different effective parameters. The mathematical model for calculating the restorable energy is expressed in the following equations

$$
\begin{gathered}
M_{1}=\sum_{i=1}^{m b} X_{s i} \times \\
\left\{\sum_{k=1}^{b l b(i)} \sum_{l=1}^{t s(k)} \lambda(k, l) A(1, l) B(1, f u m b(k))+\sum_{w=1}^{i-1} \lambda_{w} B(1, w)\right\} \times \\
\left.\operatorname{Min}\left\{\sum_{z=f l b(1)}^{f l b(i)} \sum_{p=1}^{t s(z)} L(z, p)+\sum_{v=i+1}^{m b} L_{m v}\right), \sum_{r \in \beta} Y_{r} P_{r}\right\} \\
A(i, j)= \begin{cases}1 & \text { if exist none protective object } \\
\text { in position } i \text { to } j\end{cases} \\
B(i, j)= \begin{cases}1 & \text { if exist none switching object } \\
0 & \text { in position } i \text { to } j\end{cases}
\end{gathered}
$$

The energy restoration achieved by connecting the DGs to electrical distribution systems is calculated by 


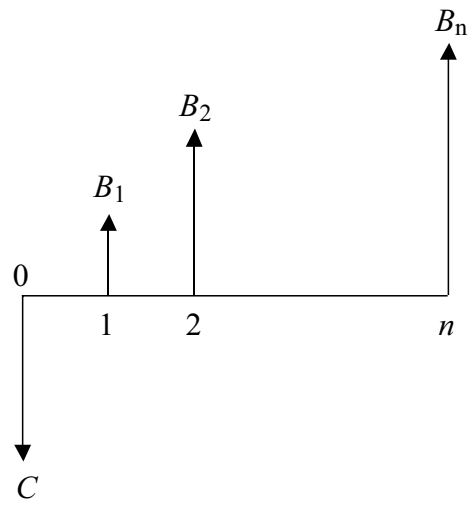

Fig. 3. Typical cash flow of the proposed method

(2) which will be explained on a typical system. In this equation, the value of M1 (the restorable loads by using the DGs) is calculated according to probability of the fault occurrence in the overhead or cable lines, the position of protective or switching devices, the capability of power generation of each DG. In the proposed method, the branches of system are categorized to two groups: main and lateral branches. When a fault occurs in the main sections, by tripping the first upstream protective device, some loads experience an interruption. To clarify this concept, the interrupted area, when a fault has occurred in a main section, is shown in Fig. 2a. As shown in this figure, the protective device 3 isolates the fault location from the system. By tripping of protective device 3, some loads installed to main or lateral sections which are located in downstream of the protective devices experience an interruption. In conventional systems, the interrupted loads cannot be restored until the repair will be completed. An appropriate idea to supply the interrupted loads is using the DGs work stand alone. If there is the DG that is capable to connect the system in necessary times, by using switch 3 , it is possible to isolate the fault area and supply the interrupted loads with DG. The restoration process and restored area as described is shown in Fig. 2b. In the restoration process, the minimum value of the capacity of power generation of DGs allocated in interrupted area and the interrupted loads can be supplied by DGs work stand alone.

Furthermore, in some conditions, due to occur a fault in the main branch, some interrupted loads can be restored only by switching and isolating the fault location. In Fig. 2c, the condition which a fault has occurred in a different main section is shown. As it can be seen in this figure, the restorable loads which can be obtained just by switch 2 and 3 have shown.

The term $\left(\sum_{w=1}^{i-1} \lambda_{w} B(1, w)\right)$ is calculating the summation of annual failure rate of all main sections while the interrupted loads can be restored with other sources such as DGs work stand alone. This term includes two parts: $\lambda_{w}$ and $B(1, w)$ indicate the failure rate of section $w$ and it is possible that restoration operations be conducted due to the fault occurrence in section $w$. By multiplying the terms $\left(\sum_{w=1}^{i-1} \lambda_{w} B(1, w)\right)$ and minimum value of interrupted loads and capacity of DGs in downstream of the corresponding section,

$\operatorname{Min}\left\{\sum_{n=f l b(1)-f l b(i)+1}^{f l b(i)} \sum_{p=1}^{t s(n)} L(n, p)+\sum_{v=i+1}^{m b} L_{m v}, \sum_{r \in \beta} Y_{r} P_{r}\right\}$,

the possible ENS decrement can be obtained. The discussed interrupted loads can be restored if and only if connecting the DGs work stand alone is created. This comparison checks the available capability and operational restoration energy.

For the lateral sections and occurrence a fault in them, the similar methodology has been used. The difference between concepts of restoration operations during the failure in lateral and main branches is relevant to performance of protective devices. During all the faults in main sections, the downstream loads experience an interruption that by using DGs and switch located in downstream the fault location can be restored. However, if in any section of a lateral branch which a protective device has been allocated, none downstream loads located in other main or lateral branches experience an interruption. The existence or none-existence of the protective device in the lateral branch is determined by auxiliary function.

It can be seen as described explanation and Fig. 2. d, the position of the protective device affects the extent of the interrupted area. If there is a DG in downstream of the discussed protective device, the restoration of a portion of the interrupted area is possible. The restoration process requires switching devices whose positions change the value of restoration energy.

Since the distribution loads have an annual growth, the value of loads should be considered in (2) by their growth rates. Also, in engineering economical concepts, time value of money is an important subject. By using profit rate, it is possible to determine the net present worth. In Fig. 3, the cash flow of applying the proposed method to a typical system is shown.

The net present worth $(N P W)$ of cash flow shown in Fig. 3 is calculated as (5). The value of $B_{i}$ is obtained by considering the value of $B_{1}$ as (6) and the summation of NPW is simplified to (8). According to (8), the parameter of $K_{1}$ is defined.

$$
\begin{aligned}
N P W & =-C+B_{1}+B_{2}+\cdots+B_{n}, \\
B_{i} & =B_{1}\left[\frac{1+\frac{r}{100}}{1+\frac{p}{100}}\right]^{i}, \\
g & =\frac{1+\frac{r}{100}}{1+\frac{p}{100}}, \\
N P W & =-C+B_{1}\left(1+\frac{g\left(g^{n-1}-1\right)}{g-1}\right), \\
K_{1} & =1+\frac{g\left(g^{n-1}-1\right)}{g-1} .
\end{aligned}
$$




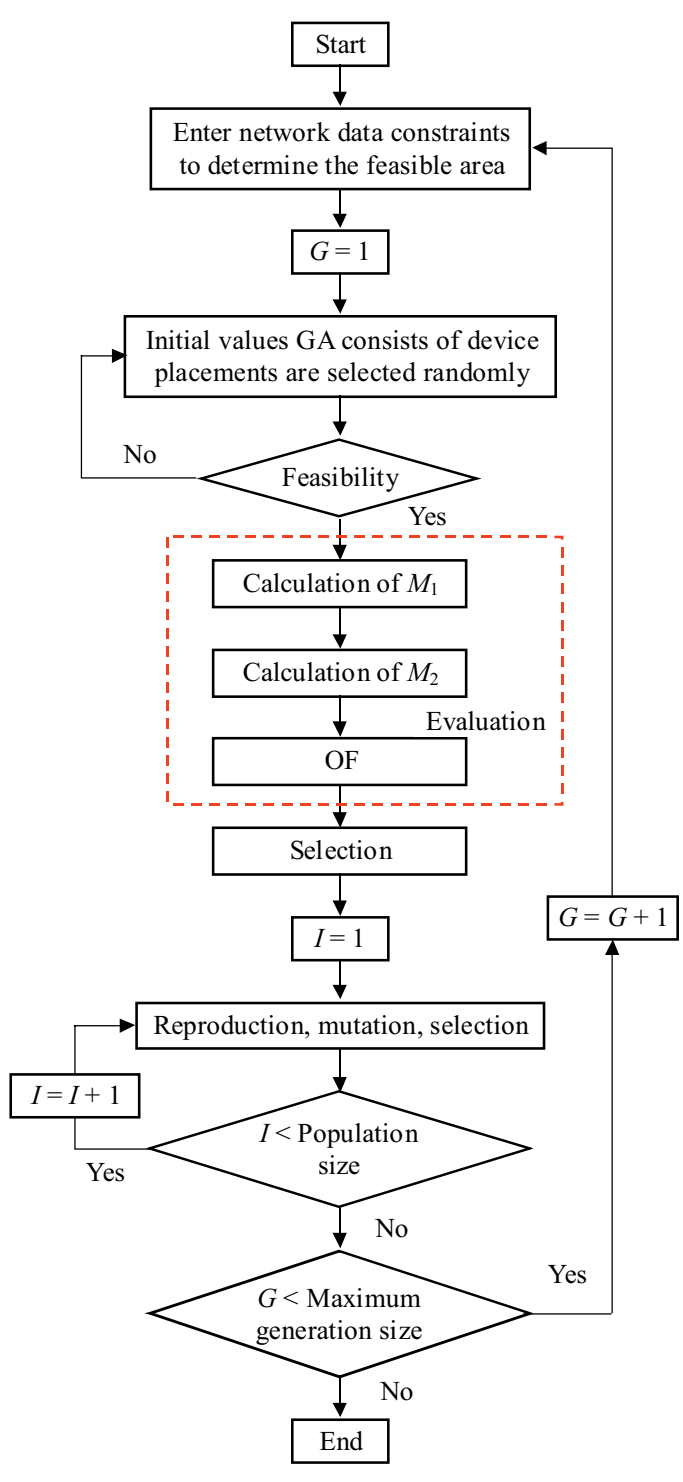

Fig. 4. Flow chart of the optimization by GA

\section{OBJECTIVE FUNCTION OPTIMIZATION}

Finding the maximum of the objective function is a nonlinear programming. The mathematical expression of the objective function is demonstrated as follows.

$$
\begin{aligned}
& \operatorname{Max} O F=K_{1} K_{2} M_{1}-\sum_{i \in \beta} Y_{i} M_{2, i}=f\left(Y_{i}\right) \\
& \text { subject to }\left\{\begin{array}{l}
Y_{i}=1 \text { or } 0 i \in \text { Possible Position } \\
\text { To } D G \text { Allocate } \\
\sum_{i \in \beta}\left(Y_{i} M_{i}\right) \leq \text { Expected Capital. }
\end{array}\right.
\end{aligned}
$$

As this problem is a nonlinear one and being somehow complex, an intelligent optimization method should be used to optimize the suggestive objective function. Genetic algorithm (GA) is selected to solve the optimization problem. GA is one of the intelligent algorithms used to optimize nonlinear programming problems such as $[10,13]$. Each possible location for connection a DG is corresponding to a gen in one chromosome. The flowchart of the optimization algorithm using GA is shown in Fig. 4.

\section{NUMERICAL RESULTS}

In this paper, an electric power distribution system of Tehran Regional Electrical Company (TREC) is selected to apply the proposed methodology of finding the optimum placement for connecting the DGs work stand alone to improve the system reliability.

The single line diagram of the test system is shown in Fig. 5. The system data are listed in Table 1. Also the position of available protective and switching devices are presented in Table 2. The other parameters that have been defined to calculate $O F$ are detailed in Table 3 . The coefficients presented in Table 3 are considered in according to experience values of TREC. Furthermore, these values are approximately similar to the considered values of $[3,6,7]$.

There are four DGs in nearby the distribution system that work stand alone. The required costs for connector lines to connect any of these DGs have been calculated by help of staffs of TREC. A number of cases for connecting the DGs to some sections are not feasible because different constraints and limitation exist such as geographic and urban barriers. For impossible cases, a great value is considered which is very distinct from other those.

The genetic algorithm to solve the optimization process is implemented using Matlab on a Pentium-IV personal computer. The optimization results are demonstrated in Table 4. The results provide the optimized placement of DGs to connect the system. Sections 27, 103, 171, 181 are four positions that by their connections to DGs, the reliability improvement would be maximized.

The optimization results obviously confirms that location of protective and switching devices directly change the affects of connecting the stand alone DGs. Any fault occurrence in main sections located in the upstream of section 27 results tripping the protective devices installed in the $63 / 20 \mathrm{kV}$ substation. If any maneuver strategy has been performed, all loads experience an overall interruption. To avoid a long interruption, using the DGs located in downstream is an appropriate choice. Because there is a switching device in section 25 , when a fault occurs in sections 1 to 25, the interrupted loads located upstream of section 25 can be restored by disconnecting the switching device 25 and connecting the DG to section 27. By comprise the DG connection to other sections such as sections 1 to 25 , it is not possible to restore any interrupted loads because the fault area cannot be isolated. Studying the other optimum DGs connections confirm the effects of the location of protective and switching devices on the restoration energy.

The results illustrate the effectiveness of the method in order to improve the cost and reliability of the distribution system. They also confirm by an additional 197540 US $\$$ investment in order to create the connector lines to connect the DGs to system, it is possible to save 8120200 
Table 1. Component data for analyzed feeder, columns: $1-$ Branch No, $2-L_{i}(\mathrm{kVA}), 3-D_{i}(\mathrm{~m}), 4-\lambda_{i}(\mathrm{~F} / \mathrm{Year})$

\begin{tabular}{|c|c|c|c|c|c|c|c|c|c|c|c|c|c|c|c|c|c|c|c|}
\hline 1 & 2 & 3 & 4 & 1 & 2 & 3 & 4 & 1 & 2 & 3 & 4 & 1 & 2 & 3 & 4 & 1 & 2 & 3 & 4 \\
\hline 1 & 0 & 80 & 0.016 & 38 & 0 & 250 & 0.05 & 75 & 0 & 20 & 0.004 & 112 & 100 & 15 & 0.003 & 149 & 0 & 200 & 0.04 \\
\hline 2 & 0 & 50 & 0.01 & 39 & 0 & 50 & 0.01 & 76 & 200 & 250 & 0.05 & 113 & 100 & 140 & 0.028 & 150 & 200 & 240 & 0.048 \\
\hline 3 & 50 & 400 & 0.08 & 40 & 0 & 350 & 0.07 & 77 & 160 & 240 & 0.048 & 114 & 200 & 230 & 0.046 & 151 & 0 & 330 & 0.066 \\
\hline 4 & 0 & 500 & 0.1 & 41 & 0 & 360 & 0.07 & 78 & 0 & 120 & 0.024 & 115 & 0 & 10 & 0.002 & 152 & 200 & 1600 & 0.32 \\
\hline 5 & 250 & 50 & 0.01 & 42 & 0 & 100 & 0.02 & 79 & 100 & 240 & 0.048 & 116 & 0 & 50 & 0.01 & 153 & 0 & 250 & 0.05 \\
\hline 6 & 0 & 400 & 0.08 & 43 & 425 & 140 & 0.028 & 80 & 315 & 160 & 0.032 & 117 & 100 & 120 & 0.024 & 154 & 200 & 150 & 0.03 \\
\hline 7 & 0 & 100 & 0.02 & 44 & 0 & 10 & 0.002 & 81 & 200 & 120 & 24 & 118 & 0 & 10 & 0.002 & 155 & 315 & 250 & 0.05 \\
\hline 8 & 200 & 200 & 0.04 & 45 & 0 & 40 & 0.008 & 82 & 0 & 380 & 76 & 119 & 25 & 350 & 77 & 156 & 100 & 60 & 012 \\
\hline 9 & 315 & 80 & 0 & 46 & 0 & 40 & 0.008 & 83 & 100 & 15 & 3 & 0 & 0 & 370 & 74 & 157 & 0 & 180 & 0.036 \\
\hline 10 & 0 & 230 & 6 & 47 & 0 & 500 & 0.1 & 84 & 25 & 70 & 14 & 21 & 0 & 360 & 72 & 158 & 50 & 150 & .03 \\
\hline 11 & 100 & 210 & 42 & 48 & 0 & 630 & 0.126 & 85 & 200 & 300 & 6 & 122 & 0 & 40 & 08 & 159 & 0 & 400 & 0.08 \\
\hline 12 & 25 & 400 & 0.08 & 49 & 50 & 10 & 0.002 & 86 & 0 & 140 & 0.028 & 123 & 0 & 30 & 0.006 & 160 & 0 & 500 & 0.1 \\
\hline 13 & 0 & 1050 & 0.21 & 50 & 200 & 600 & 0.12 & 87 & 200 & 10 & 0.002 & 124 & 0 & 50 & 0.01 & 161 & 100 & 10 & 0.002 \\
\hline 14 & 0 & 20 & 0.004 & 51 & 200 & 10 & 0.002 & 88 & 100 & 330 & 0.066 & 125 & 200 & 150 & 0.03 & 162 & 0 & 900 & 0.18 \\
\hline 13 & 0 & 20 & 0.004 & 52 & 0 & 130 & 0.026 & 89 & 0 & 140 & 0.028 & 126 & 100 & 310 & 0.062 & 163 & 0 & 60 & 0.012 \\
\hline 16 & 50 & 300 & 0.06 & 53 & 200 & 15 & 0.003 & 90 & 250 & 550 & 0.11 & 127 & 0 & 200 & 0.04 & 164 & 200 & 850 & 0.17 \\
\hline 18 & 0 & 40 & 0.008 & 54 & 500 & 100 & 0.02 & 91 & 0 & 5 & 0.001 & 128 & 100 & 300 & 0.06 & 165 & 0 & 70 & 0.014 \\
\hline 18 & 0 & 370 & 0.074 & 55 & 250 & 60 & 0.012 & 92 & 200 & 570 & 0.114 & 129 & 500 & 150 & 0.03 & 166 & 0 & 30 & 0.006 \\
\hline 19 & 50 & 15 & 0.003 & 56 & 200 & 450 & 0.09 & 93 & 0 & 1000 & 0.2 & 130 & 0 & 120 & 0.024 & 167 & 0 & 450 & 0.09 \\
\hline 20 & 200 & 100 & 0.02 & 57 & 0 & 190 & 0.038 & 94 & 0 & 30 & 0.006 & 131 & 0 & 130 & 0.026 & 168 & 50 & 450 & 0.09 \\
\hline 21 & 0 & 10 & 0.002 & 58 & 250 & 350 & 0.07 & 95 & 50 & 500 & 1 & 132 & 100 & 10 & 0.002 & 169 & 0 & 150 & 0.03 \\
\hline 22 & 0 & 30 & 0.006 & 59 & 0 & 180 & 0.036 & 96 & 0 & 350 & 0.07 & 133 & 100 & 400 & 08 & 170 & 50 & 50 & 0.01 \\
\hline 23 & 0 & 30 & 0.006 & 60 & 0 & 180 & 0.036 & 97 & 50 & 100 & 0.02 & 134 & 160 & 420 & 0.084 & 171 & 50 & 200 & 0.04 \\
\hline 24 & 0 & 100 & 2 & 61 & 500 & 350 & 0.07 & 98 & 315 & 50 & 0.01 & 135 & 0 & 60 & .012 & 172 & 0 & 120 & 0.024 \\
\hline 25 & 200 & 50 & 01 & 6 & 100 & 50 & 0 & 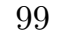 & 315 & 300 & 6 & 136 & 0 & 150 & 3 & 173 & 100 & 210 & 42 \\
\hline 26 & 100 & 210 & 0.042 & 63 & 0 & 160 & 0.032 & 100 & 200 & 300 & 0.06 & 137 & 0 & 150 & 3 & 174 & 200 & 260 & 0.052 \\
\hline 27 & 0 & 420 & 0.084 & 64 & 0 & 350 & 0.07 & 101 & 50 & 630 & 0.126 & 138 & 200 & 120 & 0.024 & 175 & 50 & 300 & 0.06 \\
\hline 28 & 315 & 80 & 0.016 & 65 & 100 & 50 & 0.01 & 102 & 0 & 10 & 0.002 & 139 & 200 & 120 & 24 & 176 & 0 & 200 & 0.04 \\
\hline 29 & 0 & 150 & 0.03 & 66 & 0 & 15 & 0.003 & 103 & 0 & 50 & 0.01 & 140 & 0 & 220 & 0.044 & 177 & 0 & 30 & 0.006 \\
\hline 30 & 100 & 420 & 0.084 & 67 & 100 & 180 & 0.036 & 104 & 0 & 60 & 0.012 & 141 & 100 & 10 & 02 & 178 & 100 & 250 & 0.05 \\
\hline 31 & 160 & 450 & 009 & 68 & 200 & 360 & 0.072 & 105 & 0 & 50 & 0 & 142 & 0 & 220 & 44 & 179 & 0 & 15 & 0.003 \\
\hline 32 & 100 & 10 & 0.002 & 69 & 100 & 420 & 0.084 & 106 & 100 & 15 & 03 & 143 & 0 & 40 & 98 & 180 & 100 & 8 & 0.0016 \\
\hline 33 & 400 & 220 & 0.044 & 70 & 200 & 240 & 0.048 & 107 & 0 & 180 & 0.036 & 144 & 0 & 120 & 0.024 & 181 & 250 & 120 & 0.024 \\
\hline 34 & 0 & 10 & 0.002 & 71 & 160 & 120 & 0.024 & 108 & 0 & 40 & 0.008 & 145 & 200 & 40 & 0.008 & 182 & 0 & 20 & 0.004 \\
\hline 35 & 315 & 150 & 0.03 & 72 & 500 & 210 & 0.042 & 109 & 250 & 60 & 0.012 & 146 & 0 & 60 & 0.012 & 183 & 200 & 250 & 0.05 \\
\hline 36 & 315 & 340 & 0.068 & 73 & 0 & 70 & 0.014 & 110 & 250 & 200 & 0.04 & 147 & 50 & 15 & 0.003 & & & & \\
\hline 37 & 400 & 200 & 0.04 & 74 & 100 & 300 & 0.06 & 111 & 0 & 15 & 0.003 & 148 & 50 & 240 & 0.048 & & & & \\
\hline
\end{tabular}

Table 2. Placement of the protective and switching devices of test system

\begin{tabular}{lr}
\hline Device type & Branch No \\
\hline Fuses & $5,16,27,28,58,105,130,131,156,160,79,97,170,171$ \\
Isolators & $25,43,45,47,60,104,143,160,177$ \\
\hline
\end{tabular}

Table 3. Objective function parameters

\begin{tabular}{ll}
\hline Objective parameter & Value \\
\hline Permanent failure rate & 20 Fault $/ 100 \mathrm{~km}$. year \\
$K_{2}$ & $1.8 \mathrm{US} \$ / \mathrm{kW}$ \\
$\beta$ & All main sections \\
$r$ & $5 \%$ \\
$n$ & 20 years \\
$p$ & $20 \%$ \\
Interruption duration & 2 hours \\
of fault occurrences & 30 minutes \\
Required time for switching & 4 \\
Number of available DGs & $4 \mathrm{MW}$ \\
$S_{D G_{i}}, i=1: 4$ & 5
\end{tabular}

US $\$$ by decreasing CENS. Since the obtained solution suggests the connection of all DGs, it is comprehensible that connecting the DGs work stand alone to proper positions improves the system reliability effectively and economically.

\section{CONCLUSION}

This paper is concerned with the improvement of the distribution systems reliability by connecting the DGs work stand alone to the system. A novel methodology has been introduced to find the optimum solution for the connecting places of DGs. This objective function is defined on the basis of the system cost including the cost of connector lines of the DGs as well as the saving costs resulted from CENS. The mathematical method is introduced to calculate ENS that is an important part of the objective function. In this paper, GA is used to optimize the objective function. The optimization process is applied to a realistic distribution system of TREC. The results illustrate that by connecting the DGs work stand alone to the appropriate places in system, the reliability system will be improved and the system cost decreased. The effec- 


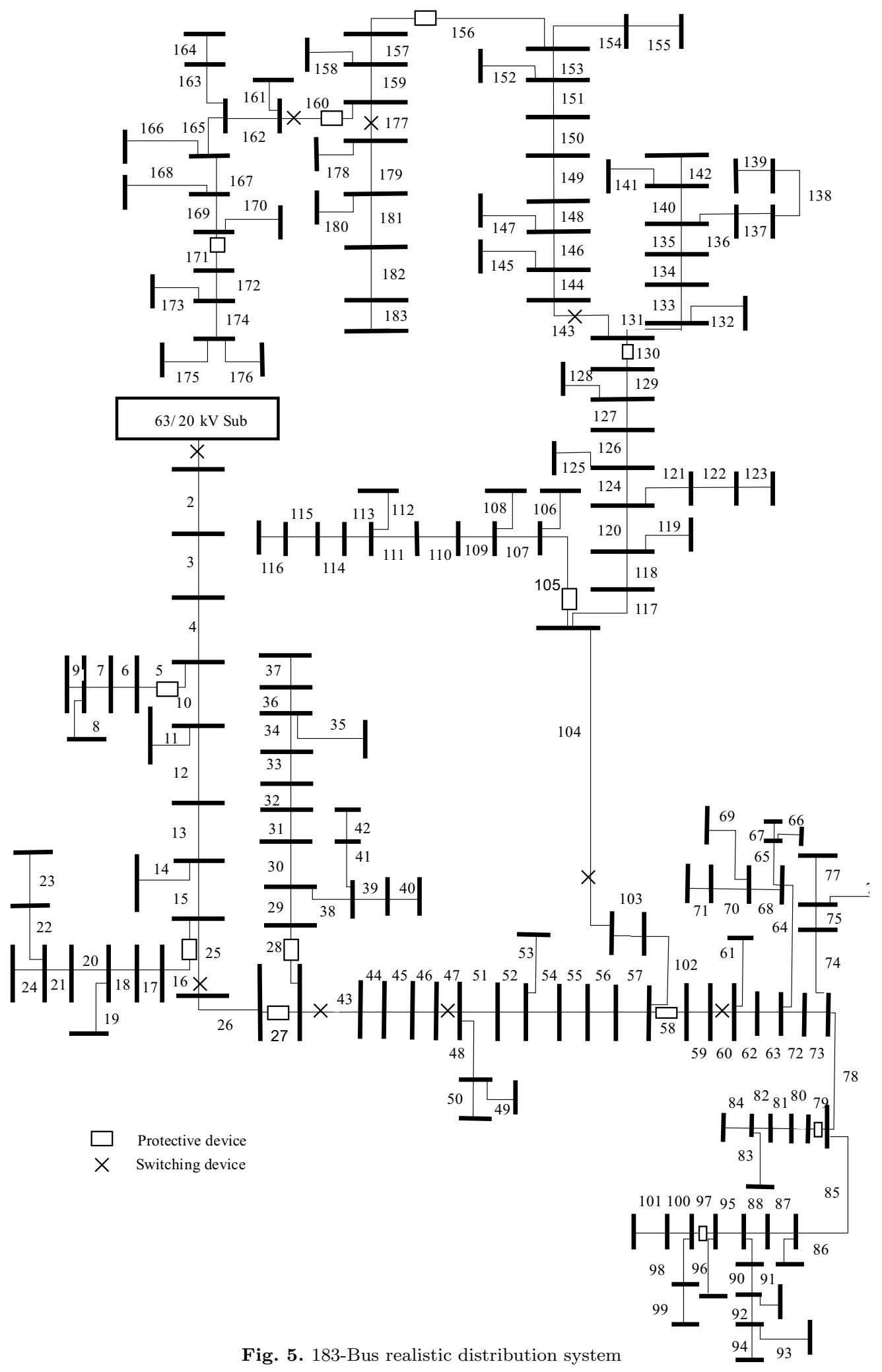

Table 4. Test results

\begin{tabular}{ll}
\hline Desired characteristics & Optimum parameters \\
\hline Appropriate places for DG allocation & $27,103,117,181$ \\
Optimized value of the objective function & 8120200 \\
Capital cost to install the maneuver lines for connecting the DGs $(\$)$ & 197540 \\
Annual restoration energy using DG connection (kW/year) & 270673 \\
\hline
\end{tabular}


tiveness of the introduced method becomes obvious from the test results.

\section{REFERENCES}

[1] BILlinton, R.-ALlAN, R. N.: Reliability Evaluation of Power System, Plenum Press, New York, 1984

[2] TIPPACHON, W.-RERKPREEDAPONG, D.: Multiobjective Optimal Placement of Switches and Protective Devices in Electric Power Distribution Systems Using Ant Colony Optimization, Electric Power System Research 79 (Mar 2009), 1171-1178.

[3] ETEmadi, A. H.-FOTUHI-FIRUZABAD, M.: Distribution System Reliability Enhancement using Optimal Capacitor Placement, IET Gener. Transm. Distrib. 2 No. 5 (2008), 621-631.

[4] CELLI, G.-PILO, F.: Optimal Sectionalizing Switches Allocation in Distribution Networks, IEEE Trans. on Power Delivery 14 No. 3 (July 1999), 1167-1172.

[5] Billinton, R.-JONNAVITHula, S.: Optimal Switching Device Placement in Radial Distribution Systems, IEEE Trans on Power Delivery 11 No. 3 (July 1996), 1646-1651.

[6] SILVA, L. G. W.-PEREIRA, R. A. F.-MANTOVANI, J. R. S. : Allocation of Protective Device in Distribution Circuits Using Nonlinear Programming Models and Genetic Algorithms, Electrical Power System Research 69 No. 1 (July 2004), 77-84.

[7] SILVA, L. G. W.-PEREIRA, R. A. F.-ABBAD, J. R.-MANTOVANI, J. R. S. : Optimized Placement of Control and Protective Devices in Electric Distribution Systems through Reactive Tabu Search Algorithm, Electric Power System Research, 78 No. 1 (Apr 2008), 372-381.

[8] CHANDRAMOHAN, S. et al: Operating Cost Minimization of a Radial Distribution System in a Deregulated Electricity Market through Reconfiguration Using NSGA Method, International Journal of Electrical Power \& Energy Systems 32 (2010), 126-132.

[9] TENG, J.-LU, C. N. : Feeder- Switch Relocation for Customer Interruption Cost Minimization, IEEE Trans. on Power Delivery 17 No. 1 (Jan 2002), 254-259.

[10] HASHEMI DEZAKI, H.-ASKARIAN ABYANEH, H.-KABIRI RENANI, Y.-AKBAR FAKHRABADI, H.-MAZLUMI, K. : Optimized Protective Devices Allocation in Electric Power Distribution Systems Based on the Current Conditions of the Devices, IEEE International Conference on Power and Energy 2010, Selangor, Malysia, 2010.

[11] POPOVIC, D. H.-GREATBANKS, J. A.-PREELJ, A.: Placement of Distributed Generators and Reclosers for Distribution Network Security and Reliability, Electric Power Systems Research 27 No. 1 (2005), 398-408.

[12] WANG, L.-SINGH, C.: Reliability-Constrained Optimum Placement of Reclosers and Distributed Generators in Distribution Networks Using an Ant Colony System Algorithm, IEEE Trans. on Systems, Man, and Cybernetics, Part C: Applications and Reviews 38 No. 6 (Nov 2008).

[13] HASHEMI DEZAKI, H.-ASKARIAN ABYANEH, H.-AGHELI, A.-HOSSEINIAN, S. H.-MAZLUMI, K.-NAFISI, H. : Optimized Investment to Decrease the Failure Rate of Distribution Lines in Order to Improve SAIFI, The 4th International Power Engineering and Optimization Conf. (PEOCO2010), IEEE Conference, Shah Alam, Selangor, Malysia, 23-24 June 2010.

[14] KAZEMI, S.-FOTUHI-FIRUZABAD, M.-SANAYE-PASAND, M.-LEHTONEN, M. : Impacts of Automatic Control Systems of Loop Restoration Scheme on the Distribution System Reliability, IET Gener. Transm. Distrib., 3 No. 10 (2009), 891-902.

[15] PREgelJ, A.-BegOVIC, M.-ROHATGI, A. : Recloser Allocation for Improved Reliability of DG-Enhanced Distribu- tion Networks, IEEE Transactions on Power Systems 21 No. 3 (Aug 2006).

[16] HUNG, D. Q.-MithulanANTHAN, N.-BANSAL, R. C. : Analytical Expressions for DG Allocation in Primary Distribution Networks, IEEE Trans. on Energy Conversion 25 No. 3 (Sep 2010), 814-820.

[17] ATWA, Y. M.-El-SAADANY, E. F.: Probabilistic Approach for Optimal Allocation of Windbased Distributed Generation in Distribution, IET Renewable Power Generation 5 No. 1 (Oct 2011), 79-88

18] KHAlesi, N.-REZAEI, N.-HAGHIFAM, M. R.: DG Allocation with Application of Dynamic Programming for Loss Reduction and Reliability Improvement, International Journal of Electrical Power \& Energy, 33 No. 2 (Feb 2011), 288-295.

19] CATRINU, M. D.-NORDGARD, D. E.: Integrating Risk Analysis and Multi-Criteria Decision Support under Uncertainty in Electricity Distribution System Asset Management, Reliability Engineering \& System Safety 96 (2011), 663-670.

[20] BROWN, R. E.-HANSON, A. P.: Impact of Two-Stage Service Restoration on Distribution Reliability, IEEE Trans. on Power Delivery 16 No. 4 (Nov 2001).

[21] SOUDI, F.-TOMASOVIC, K. : Optimized Distribution Protection Using Binary Programming, IEEE Trans. on Power Delivery 13 No. 1 (Jan 1998), 218-224.

22] SILVA, L. G. W.-PEREIRA, R. A. F.-MANTOVANI, J. R. S. : Optimized Investment to Decrease the Failure Rate of Distribution Lines in Order to Improve SAIFI, in 2010 IEEE/PES Optimization Conference \& Exposition, Malysia, ShahAlam, 2010.

Received 11 March 2012

Hamed Hashemi Dezaki was born in 1986, Borujen, Iran. He received BS and MS degrees in electrical engineering from Amirkabir University of Technology, Tehran, Iran in 2008 and 2010, respectively. Presently, he is a PhD student at the department of electrical engineering of Amirkabir University of Technology, Tehran, Iran. His main fields of research are protection of power systems, power quality and system reliability.

\section{Ali Agheli Biography not supplied.}

Behrooz Vahidi was born in Abadan, Iran, in 1953. He received the BS degree in electrical engineering from Sharif University of Technology, Tehran, Iran, in 1980, the MS degree in electrical engineering from Amirkabir University of Technology, Tehran, in 1989, and the $\mathrm{PhD}$ degree in electrical engineering from the University of Manchester Institute of Science and Technology, Manchester, UK, in 1997. From 1980 to 1986, he worked in the field of high voltage in industry as a Chief Engineer. Since 1989, he has been with the Department of Electrical Engineering of Amirkabir University of Technology, where he is now a Professor. Prof. Vahidi is senior member of IEEE His main fields of research are high voltage, electrical insulation, power system transient, lightning protection, and pulse power technology. He has authored and coauthored 250 papers and five books on high voltage engineering and power system.

Hossein Askarian Abyaneh was born in Abyaneh, Isfahan on March 20, 1953. He received the BS and MS degree both in Iran in 1976 and 1982 respectively. He also received another MS degree and PhD from UMIST, Manchester, UK in 1985 and 1988 respectively, all in power system engineering. He published over 140 scientific papers in international journals and conferences. Currently, he is a Professor with the Department of Electrical Engineering and Head of the Electrical Engineering Department, AUT, Iran, working in the area of the relay protection and power quality. 